\section{Temporal variation of faecal shedding of Escherichia coli 0157:H7 in a dairy herd producing raw milk for direct human consumption}

\author{
Giuseppe Merialdi, ${ }^{1}$ Lia Bardasi, \\ Laura Stancampiano,, Roberta Taddei,' \\ Mauro Delogu, 2 \\ Antonietta Di Francesco, ${ }^{2}$ \\ Ilaria Guarniero, ${ }^{2}$ Ester Grilli,2 \\ Mattia Fustini, ${ }^{2}$ Elena Bonfante, ${ }^{2}$ \\ Federica Giacometti, ${ }^{2}$ Andrea Serraino ${ }^{2}$ \\ ${ }^{1}$ Istituto Zooprofilattico Sperimentale \\ della Lombardia e dell'Emilia Romagna, \\ Bologna; '2Dipartimento di Scienze \\ Mediche Veterinarie, Università di \\ Bologna, Ozzano dell'Emilia (BO), Italy
}

\section{Abstract}

The objective of this study was to analyse over time the evolution of $E$. coli $0157: \mathrm{H} 7$ faecal shedding in a dairy herd producing raw milk for direct human consumption. The study was performed between October 2012 and September 2013 in an average size Italian dairy farm where animals are housed inside the barn all over the year. The farm housed about 140 animals during the study - 70 cows and 70 calves and heifers. Twenty-six animals were randomly selected from both the cows and young animals group, and faecal sampling was performed rectally six times two months apart in each animal. Eleven animals were culled during the study and a total of 285 faecal samples were collected. At each faecal sampling, three trough water samples and two trough feed samples were also collected for a total of 36 water samples and 24 feed samples. Samples were analysed by real time polymerase chain reaction (RT-PCR) and culture. Overall, 16 (5.6\%) faecal samples were positive for $E$. coli 0157 by RT-PCR. Cultural examination found 9 (3.1\%) samples positive for $E$. coli 0157; all the isolates were positive for $s t x 1, s t x$ 2 and eae genes. One (4.1\%) feed sample was positive for $E$. coli 0157 by RT-PCR; none of the water samples was positive for $E$. coli 0157 . The model highlighted a general significant reduction of the number of positive samples observed during the study from the first to the sixth sampling $(\mathrm{P}=0.000)$ and a positive relation between the presence of positive samples and average environmental temperature $(\mathrm{P}=0.003)$. The results of the study showed that in an Italian dairy farm housing animals all year, faecal shedding of $E$. coli 0157 followed the same temporal trend reported for other types of farming. The enhanced faecal shedding during warmer months may have a significant impact on environmental contamination and the safety of raw milk and its byproducts.

\section{Introduction}

The sale of raw milk for human consumption by self-service automatic vending machines has been allowed in Italy since 2004 . After a case report of haemolytic uremic syndrome related to the consumption of raw milk (Scavia et al., 2009), the Italian Health Ministry published an ordinance (10 December 2008) establishing that vending machines should bear the notice Milk must be boiled before consumption. Despite this, some consumers continue to drink raw milk (Giacometti et al., 2012d). The presence of pathogenic bacteria in raw milk has been well documented both in Europe and in the United States, but the isolation rate reported has varied considerably (Oliver et al., 2005, 2009). The most frequent pathogenic bacteria involved in outbreaks due to raw milk consumption in Europe and worldwide are Campylobacter jejuni and human pathogenic Escherichia coli (Claeys et al., 2013). E. coli 0157 was among the most frequently detected pathogenic bacteria in raw milk sold by selfservice vending machines (Giacometti et al., 2012b, 2013) in Italy, and the only reported foodborne outbreaks due to raw milk consumption were due to $E$. coli $0157: \mathrm{H} 7$ and Campylobacter jejuni (Giacometti et al., 2012a). A seasonal trend of E. coli $0157: \mathrm{H7}$ infection has been reported in humans (Renter and Sargeant, 2002; Money et al., 2010) and the increase in human infection was supposed to follow the increase in $E$. coli faecal shedding by cattle. In addition, infectious outbreaks were associated with private water supplies contaminated by bovine faeces, visits to dairy farms and cattle density in a given geographical area (Renter and Sergeant, 2002; Money et al., 2010). The seasonal variation of $E$. coli $0157: \mathrm{H} 7$ shedding in cattle faeces was previously reported but often in crosssectional studies or in farming conditions different from those common in Italian dairy herds where cattle is housed all the year long. The present study is a longitudinal analysis of the evolution of $E$. coli $0157: \mathrm{H} 7$ faecal shedding in a dairy herd producing raw milk to evaluate the potential temporal variation of raw milk contamination. Moreover, faecal shedding between young and adult animals was compared.
Correspondence: Andrea Serraino, Dipartimento di Scienze Mediche Veterinarie, Università degli Studi di Bologna, via Tolara di Sopra 50, 40064 Ozzano dell'Emilia (B0), Italy.

Tel. +39.051.2097332 - Fax: +39.051.2097346.

E-mail: andrea.serraino@unibo.it

Key words: E. coli 0157:H7, Dairy farm, Raw milk.

Acknowledgments: this research was supported by Italian Ministry of Agricultural, Food and Forestry Policies (MiPAAF) TERRAVITA project.

Conflict of interests: the authors declare no potential conflict of interests.

Received for publication: 13 February 2014.

Revision received: 6 March 2014.

Accepted for publication: 22 March 2014.

This work is licensed under a Creative Commons Attribution 3.0 License (by-nc 3.0).

@C Copyright G. Merialdi et al., 2014

Licensee PAGEPress, Italy

Italian Journal of Food Safety 2014; 3:2297

doi:10.4081/ijfs.2014.2297

\section{Materials and Methods}

The study was performed between October 2012 and September 2013 on a typical average size Italian dairy farm. The farm housed about 140 animals during the study, 70 cows (older than 24 months) and 70 calves and heifers (224 month-old). Cows and young animals were housed in two different parts of the barn: cows were housed in cubicles and divided into three groups depending on their milk yield; younger animals were housed on straw in a yard with an external paddock and grouped in five pens depending on their age. Feeding of animal groups remained the same throughout the study. Twenty-six animals were randomly selected from both the cow group and young animals group and faecal sampling was performed rectally six times two months apart in each animal. Eleven animals were culled during the study and a total of 285 faecal samples were collected. At each sampling three trough water samples and two trough feed samples were collected for cows and young animals for a total of 36 water samples and 24 feed samples. Data on rainfall and environmental temperature were collected from the website http://weather.yahoo.com/italia/emiliaromagna/bologna-711080/

\section{Escherichia coli 0157 detection}

Five grams of faeces, $25 \mathrm{~g}$ of feed and $25 \mathrm{~mL}$ of water were diluted tenfold (w/v) in buffered peptone water, and incubated at $37 \pm 1^{\circ} \mathrm{C}$ for $21 \pm 3$ h. Bacterial DNA was extracted from 1 $\mathrm{mL}$ of enriched broth using the Gen elute ${ }^{T M}$ 
bacterial genomic DNA kit (Sigma-Aldrich, St. Louis, MO, USA) as described by the manufacturer. Reference strain E. coli 0157:H7 ATCC35150 was included in each set of analysed samples as positive extraction and amplification control.

All primers and probes used in this study were described in IS0 13136:2012 and published previously (Nielsen and Andersen, 2003; ISO, 2012)

Real time PCR (RT-PCR) for the detection of E. coli 0157 serogroup-associated $r f b E$ gene was conducted in a $25 \mu \mathrm{L}$ reaction volume using the following reaction mixture: $1 \mathrm{X}$ TaqMan ${ }^{\circledR}$ Universal PCR Master mix (Applied Biosystems, Carlsbad, CA, USA), 900 nM each of the forward and reverse primers, $250 \mathrm{nM}$ of the labelled probe and $4 \mu \mathrm{L}$ DNA template. A commercially available TaqMan ${ }^{\circledR}$ Exogenous Internal Positive Control (Applied Biosystems) was included in each RT-PCR reaction. Real time-PCR thermal cycling was conducted using a StepOne Plus system (Applied Biosystems). The cycling parameters were: $95^{\circ} \mathrm{C}$ hold for 10 min for initial denaturation of the DNA and activation of the hot-start Taq polymerase, followed by 40 cycles of amplification of $95^{\circ} \mathrm{C}$ for $15 \mathrm{~s}$, and $60^{\circ} \mathrm{C}$ for $60 \mathrm{~s}$.

Positive samples were further characterised by multiplex RT-PCR targeting the virulence genes eae, stx 1 and stx 2 . In a $25 \mu \mathrm{L}$ reaction volume, the following reaction mixture was used: $1 \mathrm{X}$ Taqman ${ }^{\circledR}$ Universal PCR Master mix (Applied Biosystems), $450 \mathrm{nM}$ each of the forward and reverse primers, $100 \mathrm{nM}$ of each labelled probe and $4 \mu \mathrm{L}$ DNA template. The PCR instrument and programme were the same as those used for the previous reaction.

In addition, isolation of $E$. coli 0157 was also attempted from serogroup-specific RTPCR positive samples. Enriched faecal samples were plated on tryptone bile $\mathrm{x}$-glucuronide agar and incubated for $18-24 \mathrm{~h}$ at $37 \pm 1^{\circ} \mathrm{C}$. Up to 50 colonies with $E$. coli morphology were picked up and point-inoculated on nutrient agar. Pools of ten colonies were tested by RTPCR for E. coli 0157 detection, then colonies from positive pools were tested singly by RTPCR as described above in order to identify the E. coli 0157 strain and to detect eae, stx 1 and stx2 genes.

\section{Statistical analysis}

Data analysis was performed using Stata ${ }^{\circledR}$ 11.2 (StataCorp, College Station, TX, USA). Logistic regression random-effects models for longitudinal/panel data were built to evaluate the influence of animal age (young $v s$ adult), sampling (from first to sixth), average monthly temperature $\left({ }^{\circ} \mathrm{C}\right)$ and rainfall $(\mathrm{mm})$ on $E$. coli 0157 faecal shedding. Individual animal identifier was set as the panel variable; sampling month was set as the time variable. The rele- vant variables to be included in the final model were selected using manual backward elimination and $\log$-likelihood ratio test. Significance was set at $\mathrm{P}<0.05$. For descriptive statistics, robust standard errors allowing possible intrapanel correlations were used to calculate $95 \%$ confidence intervals.

\section{Results}

Overall 16 (5.6\%) faecal samples were positive for $E$. coli 0157 by RT-PCR examination. Cultural examination identified nine (3.1\%) samples positive for $E$. coli 0157 ; all the isolates were positive for $s t x 1, s t x 2$ and eae genes. Fourteen animals (25.9\%) were positive by RT-PCR at least once during the study, and two animals resulted positive twice. Table 1 details the prevalence of RT-PCR-positive faecal samples in young and adult animals during the study period. Table 2 shows the prevalence of RT-PCR-positive faecal samples at the six sampling times. One (4.1\%) feed sample was positive for $E$. coli 0157 by RT-PCR, but no detection could be made by cultural examina- tion; none of the water samples was positive for $E$. coli 0157 .

Logistic regression showed no significant differences between young and adult animals $(\mathrm{P}=0.671$ in the full model) or a significant influence of average monthly rainfall $(\mathrm{P}=0.613$ in the full model).

The final model highlighted a general significant reduction of the number of positive samples observed during the study from the first to the sixth sampling $(\mathrm{P}=0.000)$ and a positive relation between the presence of positive samples and average temperature $(\mathrm{P}=0.003)$, as reported in Table 3 . In detail, the final logistic regression model output showed a significant increase in $E$. coli $0157:$ H7 prevalence with temperature [odds ratio $(\mathrm{OR})>1$ ] and a significant decrease at following sampling times $(0 \mathrm{R}<1)$. Likelihood ratio test demonstrated that the full model did not perform better than the final model. Wald chisquare test confirms the significance of the final model. The prevalence predicted over time (month) by the final model is reported in Figure 1: a significant increase was observed in the summer months.

Table 1. Overall percentage of positive faecal samples (prevalence) and robust $95 \%$ confidence interval in young and adult animals.

\begin{tabular}{lccc} 
Age & Samples (n) & Prevalence (\%) & $95 \%$ CI \\
Young & 154 & 6.5 & $2.3-10.7$ \\
Adult & 131 & 4.6 & $1.3-7.8$ \\
\hline
\end{tabular}

Cl, confidence interval.

Table 2. Overall percentage of positive faecal samples (prevalence) and robust $95 \%$ confidence interval at 6 different sampling times.

\begin{tabular}{lccc} 
Sampling & Samples $(\mathrm{n})$ & Prevalence (\%) & $95 \%$ CI \\
$1^{\text {st }}$ & 52 & 15.4 & $5.3-25.5$ \\
$2^{\text {nd }}$ & 51 & 2.0 & $0.0-5.9$ \\
\hline $3^{\text {rd }}$ & 48 & 2.1 & $0.0-6.3$ \\
$4^{\text {th }}$ & 47 & 6.4 & $0.0-13.6$ \\
\hline $5^{\text {th }}$ & 46 & 4.3 & $0.0-10.4$ \\
$6^{\text {th }}$ & 41 & 2.4 & $0.0-7.3$ \\
\hline
\end{tabular}

Cl, confidence interval.

Table 3. Final logistic regression model output showing a significant increase in Escherichia coli prevalence with temperature.

\begin{tabular}{lcccccc} 
E. colt 0157 & OR & SE & Z & P & \multicolumn{2}{c}{$95 \%$ CI } \\
Temperature & 1.193132 & 0.0708786 & 2.97 & 0.003 & 1.061995 & 1.340462 \\
Sampling & 0.4937161 & 0.0966556 & -3.61 & 0.000 & 0.3363847 & 0.7246335 \\
\hline
\end{tabular}

E. coli, Escherichia coli; OR, odds ratio; SE, standard error; CI, confidence interval. Random-effects logistic regression: number of observations=285; group variable=animal; number of groups $=54$; Log likelihood=-53.380248. Likelihood-ratio test: LR chi-square $=0.56$. Assumption: final model nested in full model $\mathrm{P}=0.7548$; Wald chi-square $=13.57 \mathrm{P}=0.0011$. 


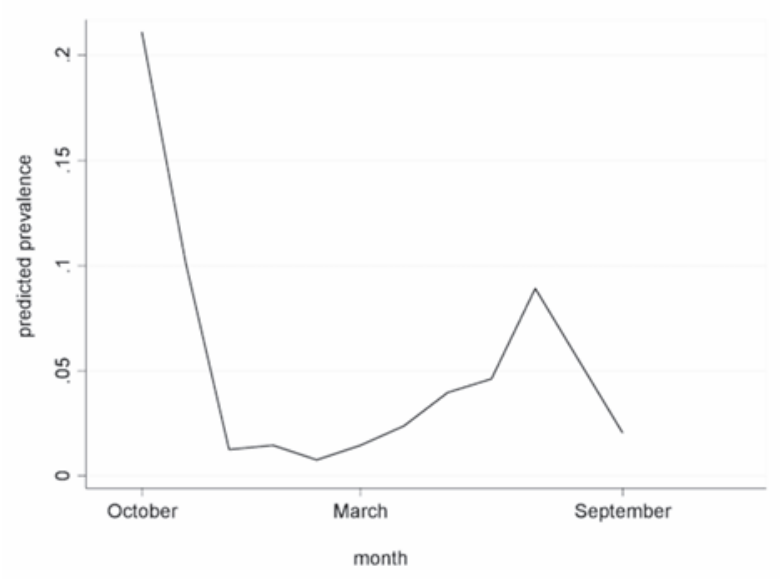

Figure 1. Prevalence predicted over time by the final logistic regression model. Prevalence is reported as proportion not percentage.

\section{Discussion}

The wordwide reported prevalence of $E$. coli 0157:H7 in cattle varies widely ranging from 1 to $28 \%$, most frequently $<5 \%$ (Renter and Sargeant, 2002). This study found E.coli 0157 prevalence rates similar to those reported by other studies on dairy herds (Stanford et al., 2005; Renter and Sargeant, 2002). Real time PCR detection of $E$. coli 0157 with a limited number of the corresponding strain isolations precludes in-depth epidemiological study based on molecular characterisation of isolates, but it is a valid indicator of the carrier condition of cattle (Fernandez et al., 2009).

Our study showed no difference in the prevalence of positive faecal samples between young and older animals, at variance with other reports of a higher prevalence of $E$. coli 0157 shedding in younger animals (Stanford et al., 2005) than in cows (18.1-22.9\% vs 10.7$11.1 \%)$. This difference is thought to be due to the type of sampling performed: the results of Stanford et al. (2005) was produced by a crosssectional study performed sampling animals of different age in five dairy farms. On the contrary, our study was a longitudinal analysis in which the same proportion of animals of different ages (calves, heifers and cows) was randomly chosen and repeatedly sampled for one year; thus, the ageing of animals during the study may have influenced the results as previously reported for Campylobacter jejuni (EllisIversen et al., 2009) and this may also explain the reduced prevalence detected during the study.

The increased prevalence of $E$. coli 0157 positive faecal samples in warmer months (from July to October) is in agreement with previous reports (Renter and Sargeant, 2002; Fernandez et al., 2009; Money et al., 2010; Stanford et al., 2005) both in cattle and dairy herds. The reason for increased $E$. coli 0157 faecal shedding during summer remains unsettled: a higher $E$. coli 0157 survival ability outside the host, the increased house fly population, environmental factors (rainfall, increased temperature, day length), changes in feeding and hormone levels in the host have been proposed (Money et al., 2010). None of these causes can be excluded in our study except for feeding changes.

A recent report (Giacometti et al., 2012c) demonstrated a relation between the detection of Verocytotoxin-producing $E$. coli in dairy herds and the general hygiene condition of the farm (feed trough, water trough and bedding cleanliness) and a higher E. coli 0157 survival ability in faeces at higher temperature (22 vs $4^{\circ} \mathrm{C}$ ) (Bach et al., 2005). The association between higher environmental temperatures and the prevalence of faecal shedding found in our study suggests that the higher survival of E. coli 0157 in faeces outside the host may play a role in enhancing $E$. coli 0157 .

\section{Conclusions}

Our study shows that in an Italian dairy farm housing animals all the year long, faecal shedding of $E$. coli 0157 followed the same temporal trend as that reported for other types of farming. The enhanced faecal shedding during warmer months may have a significant impact on environmental contamination and the safety of raw milk and its by-products.

\section{References}

Bach SJ, Stanford K, McAllister TA, 2005. Survival of Escherichia coli 0157:H7 in feces from corn- and barley-fed steers. FEMS Microbiol Lett 252:25-33.

Claeys WL, Cardoen S, Daube G, De Block J, Dewettunck K, Dierick K, De Zutter L, Huyghebaert A, Imberechts H, Thiange P, Vandenplas Y, Herman L, 2013. Raw or heated cow milk consumption: review of risks and benefits. Food Control 31:251-62.

Ellis-Iversen J, Pritchard GC, Wooldridge M, Nielen M, 2009. Risk factors for Campylobacter jejuni and Campylobacter coli in young cattle on English and Welsh farms. Prev Vet Med 88:42-8.

Fernandez D, Rodriguez EM, Arroyo GH, Padola NL, Parma AE, 2009. Seasonal variation of Shiga toxin-encoding genes (stx) and detection of E. coli 0157 in dairy cattle from Argentina. J Appl Microbiol 106:12607.

Giacometti F, Bonilauri P, Serraino A, Peli A, Amatiste S, Arrigoni N, Bianchi M, Bilei S, Cascone G, Comin D, Daminelli P, Decastelli L, Fustini M, Mion R, Petruzzelli A, Rosmini R, Rugna G, Tamba M, Tonucci F, Bolzoni G, 2013. Four year monitoring of foodborne pathogens in raw milk sold by vending machines in Italy. J Food Protect 76:1902-7.

Giacometti F, Serraino A, Bonilauri P, Ostanello F, Daminelli P, Finazzi G, Losio MN, Marchetti G, Liuzzo G, Zanoni RG, Rosmini R, 2012a. Quantitative risk assessment of verocytotoxin-producing Escherichia coli 0157 and Campylobacter jejuni related to consumption of raw milk in a province in Northern Italy. J Food Protect 75:2031-8.

Giacometti F, Serraino A, Finazzi G, Daminelli P, Losio MN, Arrigoni N, Piva S, Florio D, Riu R, Zanoni RG, 2012b. Sale of raw milk in northern Italy: food safety implications and comparison of different analytical methodologies for detection of foodborne pathogens. Foodborne Pathog Dis 9:293-7.

Giacometti F, Serraino A, Finazzi G, Daminelli P, Losio MN, Bonilauri P, Arrigoni N, Garigliani A, Mattioli R, Alonso S, Piva S, Florio D, Riu R, Zanoni RG, 2012c. Foodborne pathogens in in-line milk filters and associated on-farm risk factors in dairy farms authorized to produce and sell raw milk in Northern Italy. J Food Protect 75:1263-9.

Giacometti F, Serraino A, Finazzi G, Daminelli P, Losio MN, Tamba M, Garigliani A, Mattioli R, Riu R, Zanoni RG, 2012d. Field handling conditions of raw milk sold in vending machines: experimental evaluation of the behaviour of Listeria monocytogenes, Escherichia coli 0157:H7, Salmonella Typhimurium and Campylobacter jejuni. Ital J Anim Sci 11:132-6.

ISO, 2012. Microbiology of food and animal 
feed. Real-time polymerase chain reaction (PCR)-based method for the detection of food-borne pathogens. Horizontal method for the detection of Shiga toxin-producing Escherichia coli (STEC) and the determination of 0157, 0111, 026, 0103 and 0145 serogroups. ISO/TS Norm 13136:2012. International Organization for Standardization ed., Geneva, Switzerland.

Money P, Kelly AF, Gould SWJ, Denhoim-Price J, Threlfall EJ, Fielder MD, 2010. Cattle, weather and water: mapping Escherichia coli 0157:H7 infection in humans in England and Scotland. Environ Microbiol 12:2633-44.
Nielsen EM, Andersen MT, 2003. Detection and characterization of verocytotoxin producing Escherichia coli by automated 5', nuclease PCR assay. J Clin Microbiol 41:2884-93.

Oliver SP, Boor KJ, Murphy SC, Murinda SE, 2009. Food safety hazards associated with consumption of raw milk. Foodborne Pathog Dis 6:793-806.

Oliver SP, Jayarao BM, Almeida RA, 2005. Foodborne pathogens in milk and the dairy farm environment: food safety and public health implications. Foodborne Pathog Dis 2:115-29.

Renter DG, Sargeant JM, 2002.
Enterohemorrhagic Escherichia coli 0157: epidemiology and ecology in bovine production environments. Anim Health Res Rev 3:83-94.

Scavia G, Escher M, Baldinelli F, Pecoraio C, Caprioli A, 2009. Consumption of unpasteurized milk as a risk factor for hemolytic uremic syndrome in Italian children. Clin Infect Dis 48:1637-8.

Stanford K, Croy D, Bach J, Wallins GL, Zahiroddini H, McAllister TA, 2005. Ecology of Escherichia coli 0157:H7 in commercial dairies in southern Alberta. $\mathrm{J}$ Dairy Sci 88:4441-51. 